\title{
Aerial Photogrammetry Method for Water Quality Monitoring Using Digital Camera
}

\author{
Lim Hwee San*, Mohd. Zubir Mat Jafri and Khiruddin Abdullah
}

School of Physics, Universiti Sains Malaysia, 11800 Penang, Malaysia

\begin{abstract}
Environmental monitoring through the method of traditional ship sampling is time consuming and requires a high survey cost. This study uses an empirical model, based on actual water quality of total suspended solids (TSS) measurements from the Prai River estuary Penang, Malaysia, to predict TSS based on optical properties of digital camera imagery. The proposed algorithm is based on the reflectance model that is a function of the inherent optical properties of water, which can be related to its constituent's concentrations. Water samples were simultaneously collected with the airborne image acquisition and analyzed later in the laboratory. These locations were determined by using a handheld GPS. The digital numbers for each band were extracted corresponding to the sea-truth locations and were later used for calibration of the water quality algorithm. The efficiency of the proposed algorithm was investigated, based on the observations of correlation coefficient (R) and root-mean-square deviations (RMS) with the sea-truth data. This algorithm was then used to map the TSS concentration in Prai River estuary, Penang, Malaysia. The TSS map was color-coded and geometrically corrected for visual interpretation. This study indicates that TSS mapping can be carried out using digital camera imageries.
\end{abstract}

\section{INTRODUCTION}

Nowadays environmental pollution is of increasing concern because all the daily activities of man are related to the environment. Water pollution problem becomes increasingly critical in this present-day, whether in the developed or developing countries. Remote sensing is widely used for many scientific applications. Remote sensing is a useful and advanced technique for mapping water quality. Determination of water quality parameters using regression algorithm technique, has been adopted by many workers [1-3].

In this study, we proposed a new application of a conventional digital camera for remote sensing data acquisition. Digital images were captured from a low altitude flying aircraft of the suspected polluted areas. A new algorithm was also developed to detect and map the water pollution. Water pollution levels were detected with an acceptable accuracy by this new technique. The digital images were taken from altitude 4400 feet. Satellites and airborne imaging are widely used for mapping water quality. Due to high cost and cloud cover problem with the present airborne and satellite techniques, respectively, we introduced this new technique. This new technique used a normal digital camera as a sensor to provide remote sensing data mapping the water quality of coastal region. The traditional method that uses ship for water pollution monitoring is time consuming and requires a high operating cost $[4,5]$.

Conventionally, water pollution can be measured from ground instruments such as turbidity meters, however, this method is impractical if measurement are to be made over a relatively large area or for continuous monitoring. Field

\footnotetext{
*Address correspondence to this author at the School of Physics, Universiti Sains Malaysia, 11800 Penang, Malaysia; Tel: 6(04)6533663;

E-mail: hslim@usm.my, hslim111@yahoo.com.sg
}

measurements cannot provide fine spatial resolution maps with detailed distribution pattern over a large study area. Besides that, these studies are quite expensive and time consuming. So, remote sensing was proposed as a tool to overcome these problems. Remote sensing techniques have been used for environmental pollution applications, such as for monitoring water quality. We have considered total suspended solids (TSS) and turbidity in the water surface over Penang Island, Malaysia.

A digital camera, Kodak DC290, as shown in Fig. (1), was used as a sensor and an aircraft Cessna 172Q, as shown in Fig. (2), was used as a platform to capture images of the study area. The captured color images were then separated into three bands (red, green and blue) for multispectral analysis. Digital numbers for each band corresponding to the sea-truth data were simultaneously collected with the digital images acquisition determined for later use in the algorithm calibration analysis.

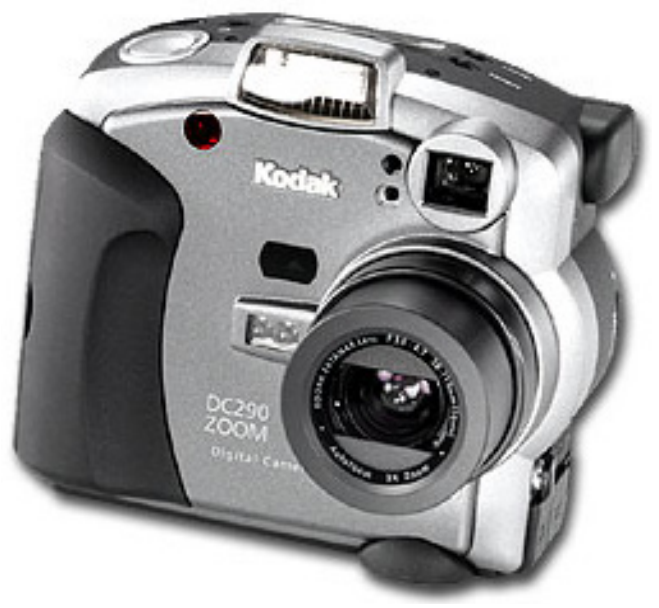

Fig. (1). Kodak DC290 digital camera used in this study. 


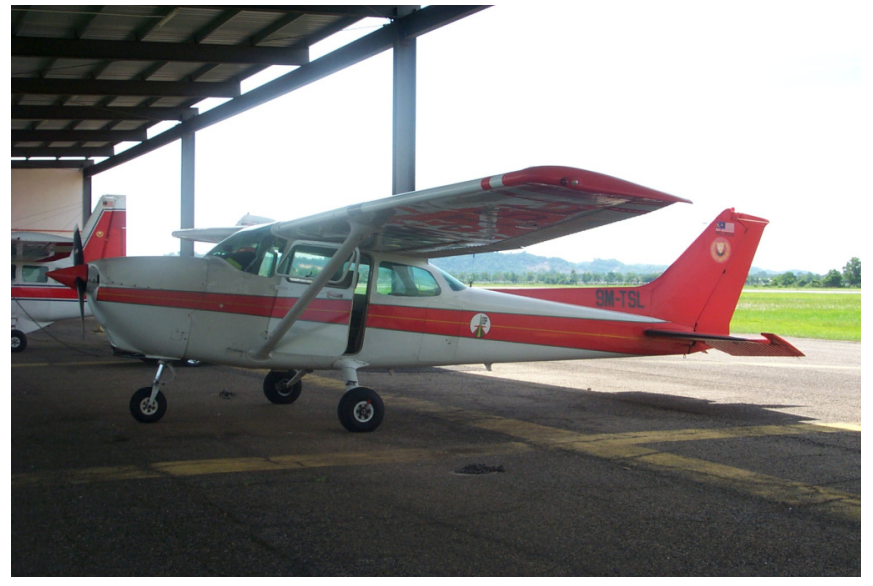

Fig. (2). Cessna 172Q aircraft used in this study.

\section{Study Area and Data Acquisition}

The study area was the Prai river estuary, Penang, Malaysia, located within latitudes $5^{\circ} 22^{\prime} \mathrm{N}$ to $5^{\circ} 24^{\prime} \mathrm{N}$ and longitudes $100^{\circ} 21^{\prime} \mathrm{E}$ to $100^{\circ} 23^{\prime} \mathrm{E}$ (Fig. 3). The images were captured from the altitude of $4400 \mathrm{ft}$ on $1^{\text {st }}$ September 2003. Water samples were collected from a small boat simultaneously with the airborne image acquisition, and later analyzed in the laboratory. The location of each water sample was determined by using a hand-held GPS.

\section{Optical Model of Water}

A new algorithm was developed for detecting and mapping water pollution from the digital camera images. The algorithm used was based on the reflectance model, that is a function of the inherent optical properties of water and this in turn can be related to the concentration of its constituents.

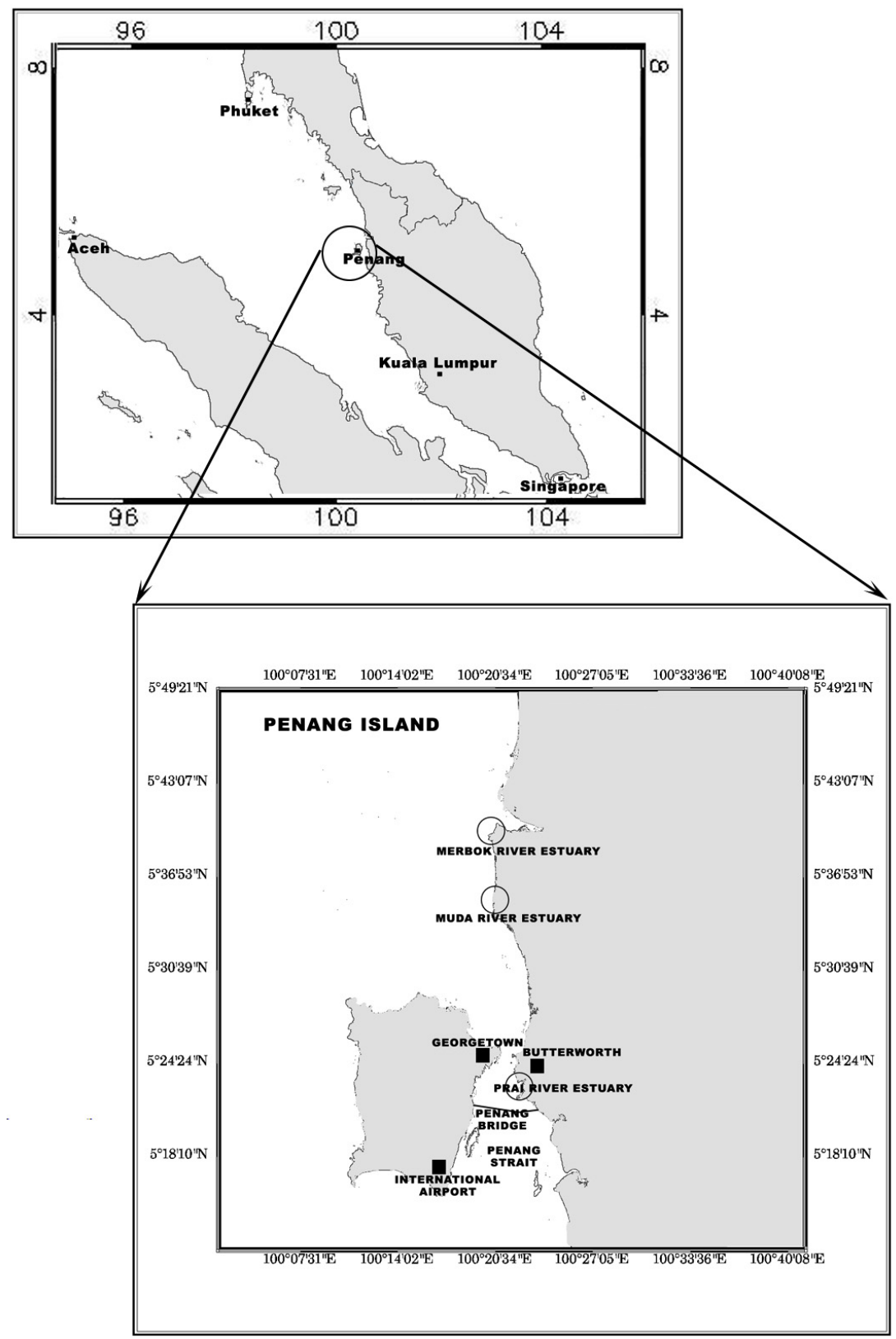

Fig. (3). The study area. 
A physical model relating radiance from the water column to the concentrations of water constituents provides the most effective way to analyze remotely sensed data for water quality studies. Remote sensing reflectance, $R$, is related to the irradiance reflectance just beneath the water surface, $R_{\text {ird }}$ [2] and is calculated as:

$$
R=\frac{(1-\rho)(1-\sigma) R_{i r d}}{n^{2}(1-r R) Q}
$$

where $\rho=$ internal Fresnel reflectance

$$
\begin{aligned}
\sigma & =\text { air-water Fresnel reflection at the interface } \\
r & =\text { water-air reflection } \\
n & =\text { refractive index (1.34) } \\
Q & =\pi
\end{aligned}
$$

Equation (1), according to [2] can be approximated as:

$$
R=0.182 \frac{R_{\text {ird }}}{Q}
$$

For estuaries water, backscatter is much less significant than absorption [6]. Therefore, the irradiance reflectance just below the water surface [7-9] is:

$$
R_{i r d}=0.33 \frac{b}{a}
$$

where,

$b=$ backscattering coefficient

$a=$ absorption coefficient

Then, equation (2) can be simplified to:

$$
R=c \frac{b}{Q a}
$$

where $c=$ constant

The inherent optical properties are determined by the contents of the water. The contributions of the individual components to the overall properties are strictly additive [10].

For a case involving a simple water quality component, suspended sediment, $\mathrm{P}$, the equation can be expressed as [11]:

$$
a(\lambda)=a_{w}(\lambda)+a_{p}(\lambda)
$$

The absorption of pure seawater is practically the same as the pure water in the visible region (400-700nm). Absorption by dissolved salts is known to be negligible in this region [10]. The absorption related to each substance is expressed as the product of its concentration, $P$ (nonchlorophyllous particles) and its corresponding specific absorption coefficients $a_{p}{ }^{*}(\lambda)$.

Therefore, the total absorption is:

$$
a(\lambda)=a_{w}(\lambda)+a_{p}^{*}(\lambda) P
$$

Similarly, for the back-scattering coefficients [12]: $\left.b_{b}(\lambda)=b_{b w}(\lambda)+b_{b p}(\lambda)\right)$

where, $b_{b w}(\lambda)$ and $b_{b p}(\lambda)$, are the back-scattering coefficients of water and suspended matter, respectively. Then:

$b_{b}(\lambda)=b_{b w}(\lambda)+b_{b p}^{*}(\lambda) P$

The symbol * denotes specific coefficients. The magnitude of $b_{b w}(\lambda)$ is $0.5 b_{w}(\lambda)$, because the molecular volumescattering function of pure sea water, $b_{w}(\lambda)$, is symmetrical [11].

For a case involving water quality component, suspended sediment, $\mathrm{P}$, the equation can be expressed as [11]:

$$
\mathrm{R}(\lambda)=R=0.33 \frac{\left(0.5 b_{b w}(\lambda)+b_{b p}{ }^{*}(\lambda) P\right)}{\left(a_{w}(\lambda)+a_{p}{ }^{*}(\lambda) P\right)}
$$

where,

$$
\begin{array}{ll}
\mathrm{b}_{\mathrm{bw}}(\lambda) & =\text { backscattering coefficient } \\
\mathrm{a}_{\mathrm{w}}(\lambda) & =\text { absorption coefficient } \\
\mathrm{a}_{\mathrm{p}}{ }^{*} & =\text { sediment specific absorption coefficient } \\
\mathrm{P} & =\text { suspended sediment }
\end{array}
$$

TSS concentration can be obtained by solving Equation (9),

$$
P=\frac{1-\frac{a_{w} R}{0.165 b_{b w}}}{-\frac{0.33 b_{b p}^{*}}{0.165 b_{b w}}+\frac{a_{p} *}{0.165 b_{b w}} R}
$$

\section{Regression Algorithm}

We have to know two parameters (the backscattering and absorption coefficients) to solve Equation 10. But these parameters were not available in the study area. So, we used regression technique to solve the equation. From Equation 10 , we can simplify the regression model as shown by Equation 11 for TSS.

$$
P=\frac{1+a_{0} R}{a_{1}+a_{2} R}
$$

where, the coefficient $a_{j}, j=0,1$ and 2 are the functions related to the coefficients used in equations (10) which are to be determined empirically from regression analysis. This equation is used to relate reflectance values from the image bands to the observed TSS concentrations. In this study, we used digital number (DN) instead of $\mathrm{R}$ values.

\section{Mosaic of the Digital Images}

Eight colored sub-scenes of the digital imageries of the Prai River Estuary were selected for algorithm calibration (Fig. 4). The digital imageries were acquired in the visible multispectral bands (3-bands: red, green and blue). The size of each color image was 1792 pixels by 1200 lines. The eight images were then mosaiced together to produce a bigger spatial coverage (Fig. 5). The mosaic image was separated into three bands (red, green and blue bands), for multispectral analysis. 

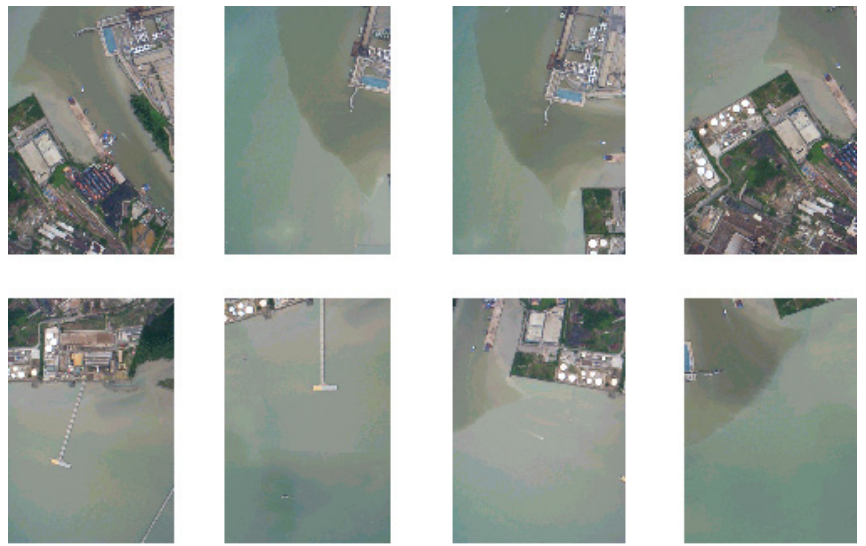

Fig. (4). Raw images used in this study.

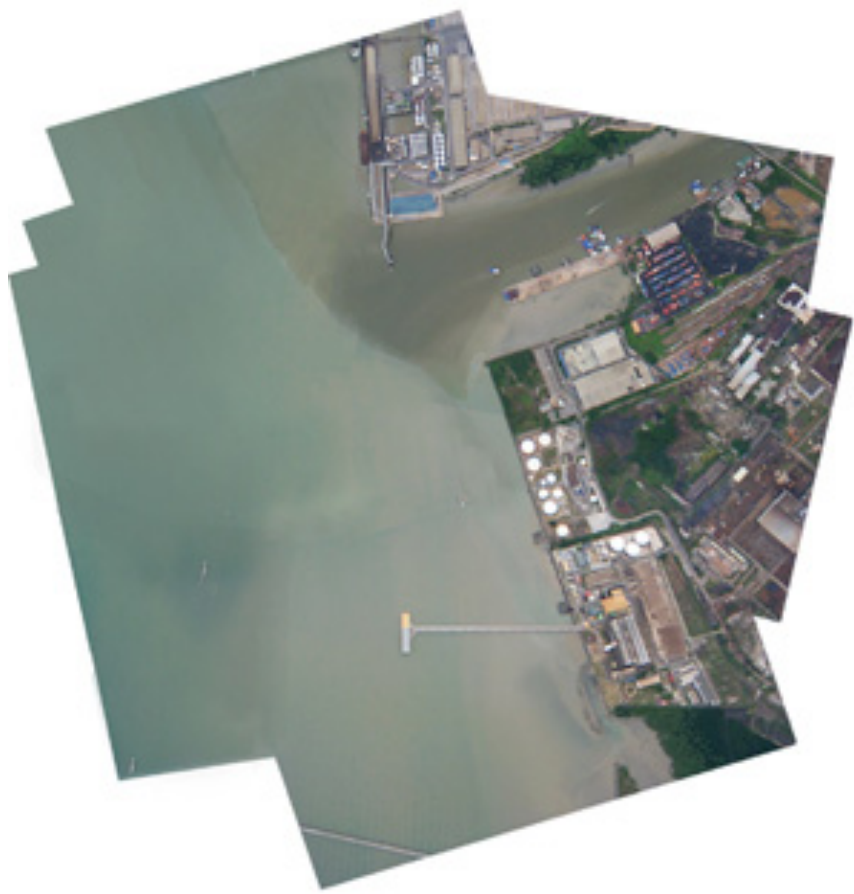

Fig. (5). The mosaic image.

The digital images were captured in absolutely clear sky condition on $1^{\text {st }}$ September 2003 and it was assumed to be $0 \%$ cloud cover because the images were captured below the cloud. Geometric correction was applied to the image using a second order polynomial equation, and then resampled by using the nearest neighborhood method. The ground control points (GCP) were determined according to the image-tomap method. Digital numbers (DN) for each location of water sample were determined for each band. Digital numbers were determined for each band using different window sizes, such as, 1 by 1,3 by 3,5 by 5,7 by 7,9 by 9 , and 11 by 11 . The DN values were extracted using the window size of 3 by 3 were used because the data produces higher correlation value.

\section{Water Quality Mapping}

The captured color images were separated into three bands (red, green and blue) for multispectral analysis. Digital number (DN) for each location of water samples was determined for each band using the corrected scene. The data points were then regressed to obtain all the coefficients of equation (11). All in situ data were combined for algorithm calibration. The coefficients of the calibrated algorithm were used to generate water quality map for study area. The generated water quality maps were also smoothed by an average filter to remove random noise. Finally, the water quality maps were geometrically corrected and color-coded for visual interpretation. The newly developed algorithm produced a high degree of accuracy with the correlation coefficient of 0.97 and the root-mean-square error of $\pm 6 \mathrm{mg} / 1$ (Fig. 6).

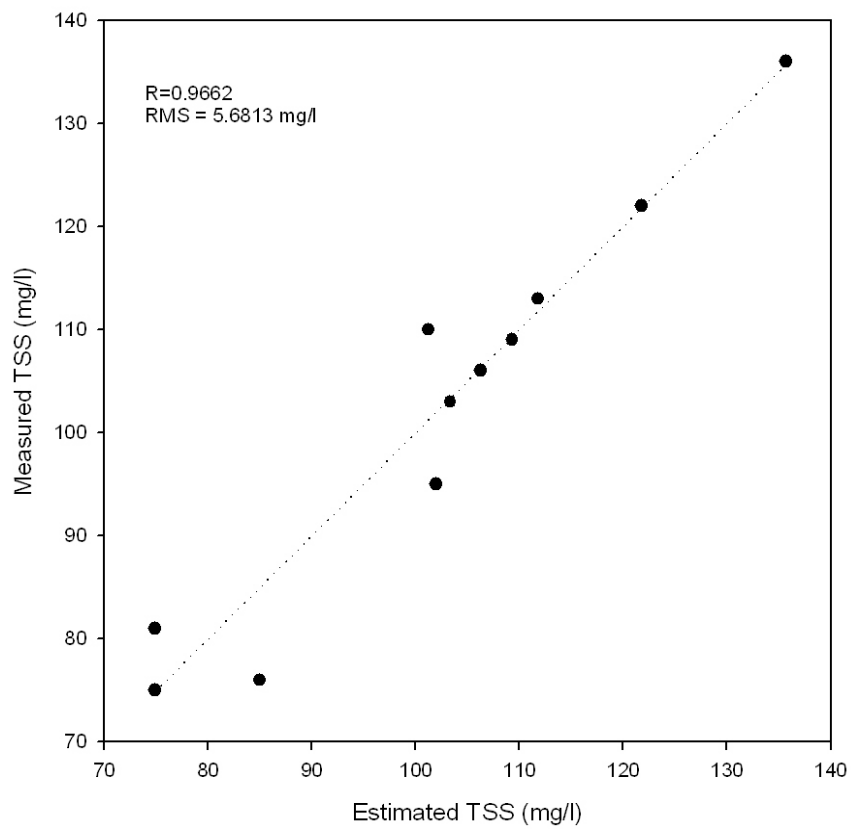

Fig. (6). Relationship between measured and estimated TSS.

\section{Validation Analysis}

For verification analysis, sea truth data were divided into two groups: half of the number of water samples were randomly selected for algorithm calibration and the other half for verification analysis. The performance of the calibrated algorithm was then evaluated. The data points from the validation data set were used in this analysis. The predicted TSS values computed by using the calibrated algorithm, were then correlated with their corresponding sea truth measurements. In this assessment analysis, the accuracy was determined by R and RMS values. The result of this analysis indicates that it is a high precision algorithm with correlation coefficient, R, of 0.92 , and RMS of about $\pm 9 \mathrm{mg} / \mathrm{l}$.

Besides that, we studied turbidity in the water using the mosaiced digital camera image. Water surface turbidity measurements were also collected. The water surface turbidity values and total suspended solids showed a linear correlation (Fig. 7). The water surface turbidity measurements are in good agreement with the TSS measurements. On the basis of the results obtained from the present study, it can be concluded that as the TSS concentration was increased, the water surface turbidity measurements were also increased (Table 1). Increasing the number of these two water quality parameters in the future analysis can be done to improve the results. 
Table 1. Measured TSS and Calculated TSS

\begin{tabular}{|c|c|c|c|}
\hline $\begin{array}{c}\text { No. } \\
\text { Sample }\end{array}$ & $\begin{array}{c}\text { Turbidity } \\
\text { (NTU) }\end{array}$ & $\begin{array}{c}\text { Measured } \\
\text { TSS (mg/l) }\end{array}$ & $\begin{array}{c}\text { Calculated } \\
\text { TSS (mg/l) }\end{array}$ \\
\hline \hline 1 & 15.0000 & 81.0000 & 74.8584 \\
\hline 2 & 12.0000 & 76.0000 & 84.9756 \\
\hline 3 & 20.0000 & 95.0000 & 101.9656 \\
\hline 4 & 21.0000 & 113.0000 & 111.7483 \\
\hline 5 & 18.0000 & 109.0000 & 109.3243 \\
\hline 6 & 25.0000 & 122.0000 & 121.7601 \\
\hline 7 & 26.0000 & 136.0000 & 135.6769 \\
\hline 8 & 19.0000 & 106.0000 & 106.2683 \\
\hline 9 & 18.0000 & 110.0000 & 101.2207 \\
\hline 10 & 15.0000 & 103.0000 & 103.3259 \\
\hline 11 & 11.0000 & 75.0000 & 74.8759 \\
\hline
\end{tabular}

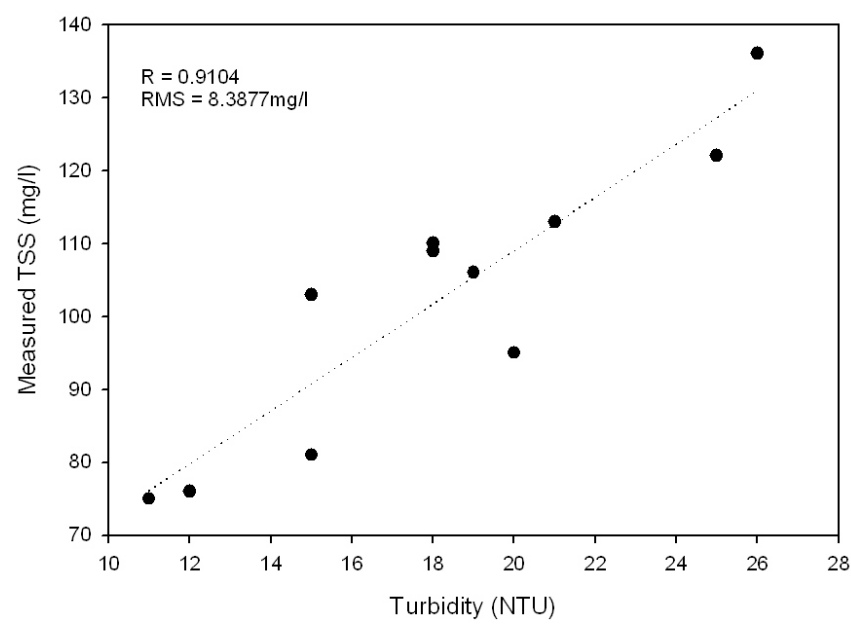

Fig. (7). Relationship between turbidity and TSS.

Fig. (8) shows the TSS map and Fig. (9) shows the turbidity map using digital camera imageries. From Fig. (8), we can see that the TSS values were high in the coastal areas and the areas in the river estuaries. Normally, TSS values in the straits of Penang were less than $300 \mathrm{mg} / \mathrm{l}$. Water quality was mapped by airborne imageries for providing a more detailed information of the studied area.

The true color digital image showed that the color near Prai River estuary was very dark compared with the surrounding areas. The generated TSS map showed low TSS value near Prai River estuary as compared with other places, (less than $100 \mathrm{mg} / \mathrm{l}$ ). This has also been proven by the lowest value of the TSS measurement from water samples analysis in the laboratory (Water sample No. 5 from Table 1). The dark color on the digital image may be caused by black sediment near Prai River estuary. Anyway, further analysis can be carried out to verify the TSS type near Prai River estuary. The water surface turbidity measurements were also showed the same pattern. The lowest water surface turbidity value was also measured near Prai River estuary (Table 1). We are quite confident with the generated TSS map by com- paring the filed measurement for the water surface turbidity and TSS parameters.

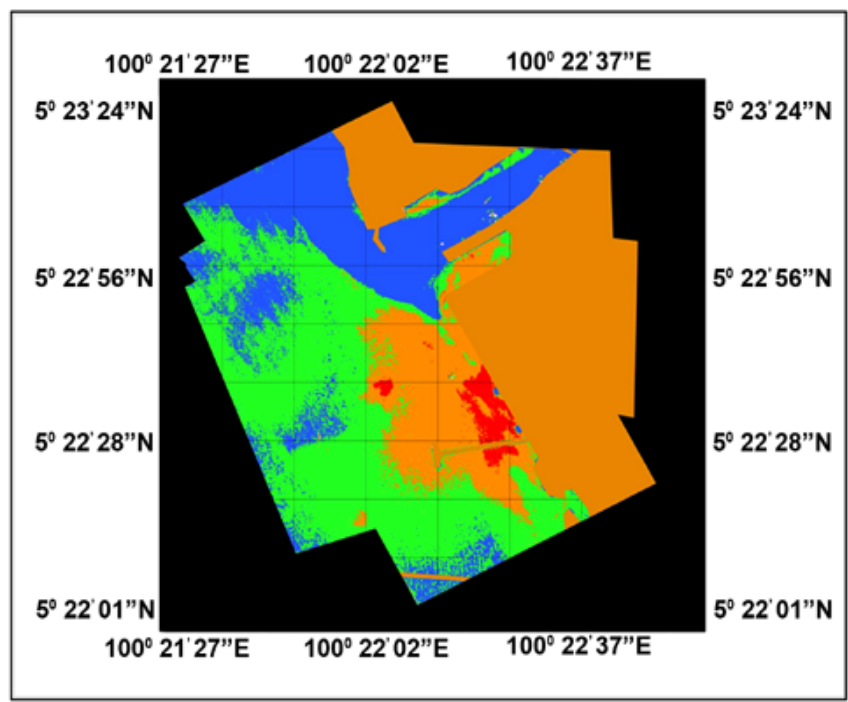

Fig. (8). Map of TSS near Prai River Estuary [Blue $=(<101 \mathrm{mg} / \mathrm{l})$, Green $=(101-150) \mathrm{mg} / \mathrm{l}$, Orange $=(151-200) \mathrm{mg} / \mathrm{l}, \mathrm{Red}=(201-$ 250) $\mathrm{mg} / \mathrm{l}$, White $=(>250) \mathrm{mg} / \mathrm{l}$, Brown $=$ Land and Black $=$ area outside image].

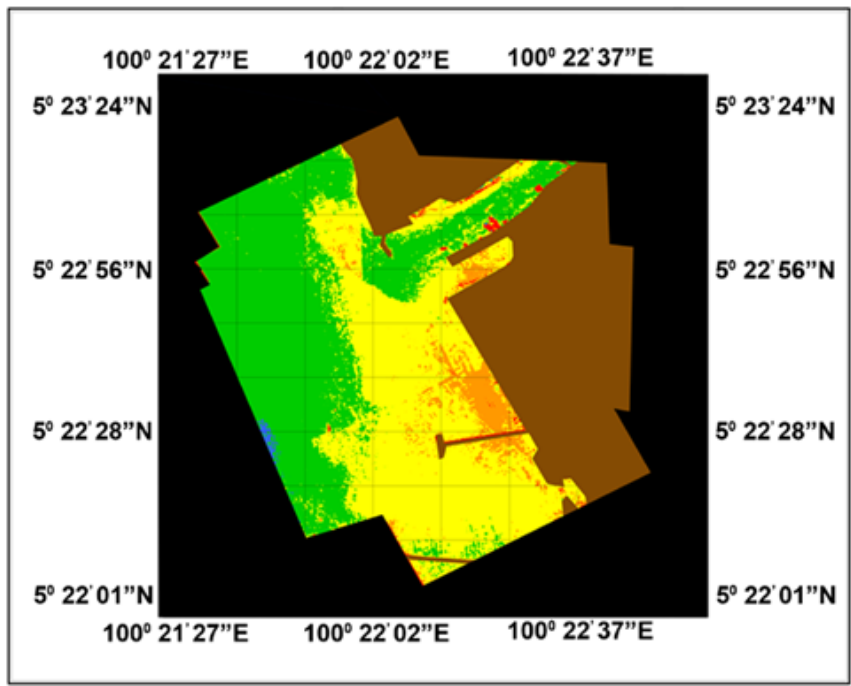

Fig. (9). Map of turbidity near Prai River Estuary [Blue $=(<10$ NTU), Green $=(10-20)$ NTU, Orange $=(20-30)$ NTU, Yellow $=$ $(30-40) \mathrm{NTU}$, Red $=(>40)$ NTU, Brown $=$ Land and Black $=$ area outside image].

\section{CONCLUSION}

Environmental pollution can be determined by remote sensing techniques. Conventional digital camera can be used as a sensor in remote sensing studies and it can provide very useful information for estimating and mapping the water 
pollution. We have successfully utilized digital camera imageries for water pollution studies. This technique can overcome the problem of cloud-cover scenes at the Equatorial region. The proposed technique also gives an alternative airborne data acquisitions to provide low cost digital imageries for remotely sensed application. The proposed methodology is very cheap, where only a digital camera is used. The cost is only on renting a light aircraft. The proposed algorithm produced high accuracy with high $R$ value of 0.97 and low RMS value of $\pm 6 \mathrm{mg} / \mathrm{l}$. A TSS map was successfully generated using the proposed developed algorithm. Finally, with this new technique the problem of detecting water pollution can be overcome. Future studies on water pollution are very much needed, because the quality of water is getting worse every day. It is important to have more detailed information on the quality of our environment. Besides that, information about pollution level can be used by many sectors such as the tourism industry, environmental, public and other related sectors.

\section{ACKNOWLEDGEMENT}

This project was carried out using the Malaysian Government IRPA grant no. 08-02-05-6011, ESCAP-NASDA grant and USM short term grants. We would like to thank the technical staff and research officers who participated in this project. Thanks are extended USM for support and encouragement. The facilities of Universiti Sains Malaysia are used to pursue this project.

\section{REFERENCES}

[1] Dekker AG, Vos RJ, Peters SWM. Analytical algorithms for lakes water TSM estimation for retrospective analyses of TM and SPOT sensor data. Int J Remote Sens 2002; 23(1): 15-35.

[2] Doxaran D, Froidefond JM, Lavender S, Castaing P. Spectral signature of highly turbid waters application with SPOT data to quantify suspended particulate matter concentrations. Remote Sens Environ 2002; 81: 149-61.

[3] Tassan S. An improved in-water algorithm for the determination of chlorophyll and suspended sediment concentration from Thematic Mapper data in coastal waters. Int J Remote Sens 1993; 14(6): 1221-9.

[4] Forget P, Ouilion S. Surface suspended matter off the Rhone river mouth from visible satellite imagery. Oceanol Acta 1998; 21(6): 739-49.

[5] Forster B, Xu BD, dan Sha XW. Satellite remote sensing of pollution and its distribution in near-coastal waters. Asian Pac Remote Sens J 1993; 6(1): 1-10.

[6] Gohin F, Druon JN, Lampert L. A five channel chlorophyll concentration algorithm applied to SeaWiFS data processed by SeaDAS in coastal waters. Int J Remote Sens 2002; 23(8): 1639-61.

[7] Morel A, Prieur L. Analysis of variation of ocean color. Limnol Oceanogr 1977; 22: 709-22.

[8] Siddorn JR, Bowers DG, Hoguane AM. Detecting the Zambezi river plume using observed optical Properties. Mar Pollut Bull 2001; 42(10): 942-50.

[9] Kirk JTO. Dependence of relationship between inherent and apparent optical properties of water on solar altitude. Limnol Oceanogr 1984; 29 : 350-6.

[10] Gallegos CL, Correl DL. Modeling spectral diffuse attenuation, absorption and scattering coefficients in a turbid estuary. Limnol Oceanogr 1990; 35: 1486-502.

[11] Gallie EA, Murtha PA. Specific absorption and backscattering spectra for suspended minerals and chlorophyll-a in Chilko Lake, British Columbia. Remote Sens Environ 1992; 39: 103-18.

[12] Prieur L, Sathyendranath S. An optical classification of coastal and oceanic waters based on the specific spectral absorption curves of phytoplankton pigments, dissolved organic matter and other particulate materials. Limnol Oceanogr 1981; 26: 671-98. 